\title{
Diversity of arbuscular mycorrhizal fungal spore communities and its relations to plants under increased temperature and precipitation in a natural grassland
}

\author{
SUN XiuFeng ${ }^{1}$, SU YuanYing ${ }^{2}$, ZHANG Ying ${ }^{2}$, WU Ming Yu ${ }^{1}$, ZHANG Zhe $^{1}$, PEI KeQuan ${ }^{1}$, \\ SUN LiFu ${ }^{1,3}$, WAN ShiQiang ${ }^{1} \&$ LIANG Yu $^{1 *}$ \\ ${ }^{1}$ State Key Laboratory of Vegetation and Environmental Change, Institute of Botany, Chinese Academy of Sciences, Beijing 100093, China; \\ ${ }^{2}$ State Key Laboratory of Mycology, Institute of Microbiology, Chinese Academy of Sciences, Beijing 100101, China; \\ ${ }^{3}$ College of Life Sciences, Shaoxing Universtiy, Shaoxing 312000, China
}

Received May 14, 2013; accepted June 3, 2013; published online July 25, 2013

\begin{abstract}
Arbuscular mycorrhizal fungi (AMF) form mutualisms with most plant species, and therefore, understanding how AMF communities will respond to climate change is essential for predictions of changes in plant communities. To evaluate the impact of global climate change on AMFs and plant-AMF interactions in a natural grassland in Inner Mongolia, both artificial warming and watering treatments were assigned to experimental plots. Our results indicate that (1) warming and precipitation significantly affected the relative spore abundance of abundant sporulating AMF species; (2) the relative abundance of weak sporulating AMF species and AMF diversity decreased under experimental warming; (3) evidence was found that the composition of the AMF community in a given year might be correlated with plant community composition in the following year; and (4) grasses and forbs showing different preferences to Claroideoglomus etunicatum or Ambispora gerdemannii dominated plots. Our results imply that climate change appears to induce changes in AMF assemblages with knock-on effects on grassland plant communities. AMF communities may play a much more important role than we have thought in the responses of ecosystem to global climate changes.
\end{abstract}

global warming, precipitation increase, Arbuscular mycorrhiza, plant-AMF relations, grassland ecosystem

Citation: Sun X F, Su Y Y, Zhang Y, et al. Diversity of arbuscular mycorrhizal fungal spore communities and its relations to plants under increased temperature and precipitation in a natural grassland. Chin Sci Bull, 2013, 58: 4109-4119, doi: 10.1007/s11434-013-5961-5

Climate change refers to any change in climate over time, whether due to natural variability or as a result of human activity [1]. In the next century, global mean temperature is predicted to increase by $1.8-4.0^{\circ} \mathrm{C}$, and mean annual precipitation is also predicted to change in many area of the world [1]. To understand the consequences of global climate change, research into how different ecosystems and their components will respond to global warming and altered precipitation patterns is essential. Grasslands are one of the most important ecosystems in the world, occurring in almost all climatic zones and covering nearly $20 \%$ of the global land surface [2]. In China, grasslands cover approx-

*Corresponding author (email: coolrain@ibcas.ac.cn) imately $4 \times 10^{8} \mathrm{hm}^{2}, 41.7 \%$ of the Chinese territory. The majority of these grasslands are found in northern China [3] under a semi-arid to arid cold climate. Both temperature and precipitation limit the productivity of agriculture and animal husbandry in these areas [4]. As many components of grassland ecosystems, including composition of aboveground plant community [5,6], root performances and lifespan [7], structure of soil microbial community [8,9], and soil and microbial respiration [10-12] are very sensitive to climatic change, understanding how grasslands will change with changing climatic conditions is essential for the sustainable development of agriculture and stockbreeding in northern China. Mycorrhizal fungal communities are an important component of grassland ecosystems and act as a 
carbon sink for up to $15 \%$ of primary production [13]. Grasses often form symbioses with arbuscular mycorrhizal fungi (AMF) [14], and AMF abundance tends to be much higher in grasslands than in other ecosystems [15]. Characterization of the mycorrhizal community could therefore be crucial for understanding the response of grassland ecosystems to climate changes $[16,17]$.

While field studies have examined the effects of elevated $\mathrm{CO}_{2}$ on mycorrhizal communities, little research has addressed the effects of other environmental factors, such as temperature and precipitation [16,17]. Similarly, most field experiments testing for warming effects in natural ecosystems have focused on changes in the aboveground vegetation, rather than the mycorrhizal fungal communities [17]. While enhanced extraradical mycelium (ERM) and root colonization of AMF have been observed in some warming experiments $[18,19]$, increased temperature also showed negative or no significant effects on AMF in other studies $[20,21]$, and the variety of heating approaches, the different ecosystems studied and the distinct consequences of warming such different systems may be reasons for such different results [22]. To better predict how grasslands will respond to a changing climate, studies of how key environmental factors, such as temperature and precipitation, influence the growth and reproduction of AMF are critical [21]. It is also necessary to quantify how much variation exists in the response of different AMF species to factors of environmental change such as soil temperature and moisture, as both plant and fungal species show differential migratory capabilities [16].

Since the diversity of AMF plays a key role in plant biodiversity and ecosystem functioning [23,24], it will be important to understand its responses to climate change. Biogeographic patterns of AMF species occurrence along environmental gradients suggest that temperature and moisture control both the distribution of AMF communities [25-27], However, the immediate responses of AMF communities in natural ecosystems to global warming and altered precipitation rates remain poorly understood.

Spore morphology methods were mainly used before the molecular methods introduced in studying AMF community. Although molecular methods such as DNA cloning and sequencing, DGGE, T-RFLP, and pyrosequencing revolutionized AMF research, due to the PCR bias, it is a little difficult for quantitative analysis of AMF. Therefore spore morphology methods still has its advantage in quantitative analysis of AMF among different experimental treatments [28]. Spore records are subject to bias because sporulation of AMF depends on biotic and abiotic conditions, and AMF species in the "spore community" may thus not always reflect their abundance in soils or plant roots [29]. However, sporulation is an important aspect of AMF life cycles and essential to propagule availability and even survival of AMF species, it is necessary to know the response of "spore community" to environmental factors when evaluate the impact of climate change on AMF community.

In this study, we investigated how higher temperatures and increased precipitation influence the spore production and colonization structures of mycorrhizal fungi. Infrared heaters were used to increase temperatures, and $120 \mathrm{~mm}$ water (about $30 \%$ of mean annual precipitation) was added to experimental plots to mimic the future warmer and wetter conditions.

The specific questions addressed were: (1) Are there any effects of increased temperature and precipitation on spore production and colonization of AMF communities in grasslands? (2) Does the spore production of different AMF species, including both spore-abundant and non-abundant species, respond similarly to environmental change? If not, how and to what extent do warmer temperatures and increased precipitation affect mycorrhizal communities in grassland ecosystems? (3) Since global climate change may affect both plant and AMF communities, will the relationship between plant and AMF communities be altered under the climatic conditions of the future?

\section{Materials and methods}

\subsection{Study site}

The study site was situated in a natural grassland in Duolun County of Inner Mongolia $\left(42^{\circ} 02^{\prime} \mathrm{N}, 116^{\circ} 17^{\prime} \mathrm{E}, 1324 \mathrm{~m}\right.$ a.s.l.). The mean annual precipitation in this area is 387.2 mm, with peaks in July and August. The mean monthly air temperature ranges from $-15.9^{\circ} \mathrm{C}$ in January to $19.9^{\circ} \mathrm{C}$ in July, with an annual average of $2.1^{\circ} \mathrm{C}$. Mean monthly soil surface temperatures parallel the air temperatures, and range from $-16.3^{\circ} \mathrm{C}$ in January to $24.2^{\circ} \mathrm{C}$ in July. The soils in the study sites are chestnut (Chinese classification) or Calcicorthic Aridisol (US soil taxonomy classification system). The total organic carbon and total nitrogen determined in 2006 are $15.4 \pm 1.9$ and $1.51 \pm 1.77 \mathrm{mg} \mathrm{g}^{-1}$ in soil. The $\mathrm{pH}$ of the soil is $6.84 \pm 0.07$, and the bulk density is $1.31 \pm 0.03$ $\mathrm{g} \mathrm{cm}^{-3}$.

The experiment plots were established in a fenced grassland dominated by native grasses, Chloris virgata Swartz, Cleistogenes squarrosa Keng, Eragrostis pilosa Beauv., Gagea pauciflora Turcz., Gueldenstaedtia stenophylla Bunge, Leymus chinensis Tzvel., Melilotoides ruthenica Sojak, Potentilla spp., Setaria viridis Beauv, and Stipa krylovii Roshev [30].

\subsection{Field treatments}

The experimental design is described in detail in Niu et al. [30]. The experiment used a paired, nested design with precipitation as the primary factor and warming as the secondary factor. There were three pairs of $10 \mathrm{~m} \times 15 \mathrm{~m}$ plots: one plot in each pair was assigned as the increased precipitation treatment and the other as the control. At each precipitation 
plot, $15 \mathrm{~mm}$ of water was added weekly in July and August using a watering system to mimic a $120 \mathrm{~mm}$ increase in precipitation (about $30 \%$ of the mean annual precipitation at the study site). Within each $10 \mathrm{~m} \times 15 \mathrm{~m}$ plot, four $3 \mathrm{~m} \times 4 \mathrm{~m}$ subplots were treated as the warmed and control subplots with two replicates. The subplots were randomly assigned to warming or control treatments. Artificial heating of plots in the field was accomplished with $1600 \mathrm{~W}$ overhead $(2.5 \mathrm{~m}$ in height) infrared heaters (MSR-2420 infrared radiators, Kalglo Electronics Inc, USA) and a power input was about $100 \mathrm{~W} \mathrm{~m}^{-2}$. Mean temperatures at $10 \mathrm{~cm}$ soil depth from May of 2005 to December of 2006 in control, W (warming), $\mathrm{P}$ (increased precipitation) and WP (warming plus increased precipitation) treatments are $7.15,8.47,7.04$, and $8.09^{\circ} \mathrm{C}$, respectively.

\subsection{Sampling procedure}

One soil cylinder (15 cm in depth, $8 \mathrm{~cm}$ in diameter) were taken from each plot at the beginning (May 25), middle (August 1), and end (September 22) of the growing season in 2005, and in the middle of the growing season (August 4) in 2006. All live roots were collected in each soil cylinder for determining AM colonization. Soil samples were stored at $4^{\circ} \mathrm{C}$ prior to spore isolation.

\subsection{AM structure examination}

Root samples were rinsed with tap water, cleared in $10 \%$ (w/v) $\mathrm{KOH}\left(20 \mathrm{~min}, 92^{\circ} \mathrm{C}\right)$, acidified in lactic acid $(3 \mathrm{~min})$, and stained $\left(20 \mathrm{~min}, 92^{\circ} \mathrm{C}\right)$ with $0.5 \%$ acid fuchsin. Fifty root fragments ( $\mathrm{ca} 1 \mathrm{~cm}$ long) were mounted on slides in a polyvinyl alcohol solution [31] and examined with a compound microscope (Olympus BH-2) at $\times 100-400$ magnification for the presence of AM fungal structures (i.e. arbuscules, vesicles, hyphal coils, and intercellular nonseptate hyphae). The percentage of root length colonized by AMF structures was estimated according to the magnified line-intersect method [32].

\subsection{Spore separation and identification}

Arbuscular mycorrhizal fungal spores were isolated from the soil using the wet-sieving and decanting method of Gerdemann and Nicolson, modified by Daniels and Skipper [33]. AMF were identified according to current taxonomic criteria [34-37], and information given on the INVAM web page (http://www.invam.caf.wvu.edu). At least 20 spores of each species were used for identification. Morphological characteristics were first determined in water, and then in Melzer's reagent. Cotton blue was also used to aid identification. Permanent slides were prepared with Polyvinyl-lacto-glycerol (PVLG), sealed with nail varnish, and stored in the Herbarium Mycologicum Academiae Sinicae (HMAS) in Beijing.

\subsection{Spore composition of the AMF community}

The relative abundance (RA) of mycorrhizal fungal species was calculated as $R A_{i}=N_{i} / N$, where $N_{i}$ is the spore number of species $i$, and $N$ is the total spore number of all AMF species in one 100-g air dried soil sample. The difference in relative abundance (DRA) between two mycorrhizal fungal species was calculated as DRA $=R A_{1}-R A_{2}$, where $R A_{1}$ and $R A_{2}$ are the relative spore abundances of species 1 and species 2 , respectively. Relative abundance of infrequent sporulating species was defined as sum of 1 minus RA of three spore dominant species (Claroideoglomus etunicatum, Ambispora gerdemannii, and Glomus albidum).

The species diversity of mycorrhizal communities was estimated using Simpson's diversity index $(H): H=1-\sum p_{i}^{2}$, where $p_{i}$ is the relative proportion of spores of species $i$ in the community [38]. Seasonal changes in DRA, the relative abundance of non-dominant species, and $H$ were calculated as the difference between middle and early samples (first half of the growing season), and between the final and middle samples (second half of the growing season). Interannual changes of these measures were calculated as the difference between those of the mid-season samples of 2006 and 2005 .

\subsection{Statistical analysis}

Mantel tests were conduct with the PC-ORD version 5 [39] to test for a correlation between plant and AMF community composition in 2005 and 2006. The significance of the standardized Mantel statistic ( $r$ ) was evaluated by randomization (1000 Monte-Carlo permutations). Effects of year and season on relative abundances of different AMF species and impacts of precipitation and warming on intra- and inter-annual changes of abundant sporulating species, total relative abundance of infrequent sporulating species and Simpson's diversity index of AMF spore community were evaluated using general linear model in SPSS (SPSS for windows, version 16.0, SPSS Inc, Chicago, USA). Impacts of Block, precipitation, warming, and sampling time on colonization of AM structures were evaluated using the repeated-measures ANOVA (aov function) in $\mathrm{R}$ software (version 2.12.2). Indicator species analysis was carried out using PC-ORD version 5 [39] to assess the preferences of AMF spores to warming, precipitation increase and seasons [40].

\section{Results}

\subsection{AMF colonization in response to heating and wa- tering}

Arbuscular mycorrhizal structures were observed in all collected roots (Table 1). However, there were no significant differences in the quantity of AM structures or in the percentage of root length colonized (PRLC) by AM fungal 
Table 1 Density of vesicles, arbuscules, hyphal coils, and percentage root length colonization (PRLC) of AMF ${ }^{a}$ )

\begin{tabular}{|c|c|c|c|c|}
\hline Treatment ${ }^{\text {b) }}$ & Vesicles (No./cm) & Arbuscules (No./cm) & Hyphal coils (No./cm) & PRLC (\%) \\
\hline \multicolumn{5}{|l|}{ May 25,2005} \\
\hline Control & $11.4 \pm 1.8$ & $38.1 \pm 8.8$ & $4.5 \pm 0.6$ & $73.2 \pm 4.4$ \\
\hline \multicolumn{5}{|l|}{ Aug. 1, 2005} \\
\hline Control & $6.6 \pm 2.4$ & $11.8 \pm 5.5$ & $4.7 \pm 1.7$ & $53.0 \pm 6.1$ \\
\hline Warming & $4.3 \pm 1.5$ & $3.9 \pm 0.9$ & $3.3 \pm 1.1$ & $50.3 \pm 2.8$ \\
\hline Precipitation increase & $9.2 \pm 1.9$ & $5.1 \pm 1.3$ & $3.1 \pm 0.7$ & $40.0 \pm 2.9$ \\
\hline \multicolumn{5}{|l|}{ Sep. 22, 2005} \\
\hline Control & $6.3 \pm 3.0$ & $15.5 \pm 6.2$ & $2.7 \pm 0.7$ & $58.2 \pm 8.7$ \\
\hline Warming & $5.4 \pm 1.3$ & $13.6 \pm 4.3$ & $2.1 \pm 0.8$ & $62.3 \pm 5.2$ \\
\hline Precipitation increase & $6.2 \pm 2.5$ & $8.4 \pm 3.6$ & $5.2 \pm 3.3$ & $47.7 \pm 8.6$ \\
\hline \multicolumn{4}{|l|}{ Aug. 4, 2006} & $45.7 \pm 7.3$ \\
\hline Control & $5.2 \pm 1.7$ & $1.0 \pm 0.9$ & $1.4 \pm 0.7$ & $39.3 \pm 8.8$ \\
\hline Warming & $5.9 \pm 2.4$ & $2.6 \pm 2.0$ & $0.6 \pm 0.2$ & $29.9 \pm 5.7$ \\
\hline Precipitation increase & $6.1 \pm 2.4$ & $0.4 \pm 0.2$ & $0.8 \pm 0.4$ & $37.3 \pm 8.4$ \\
\hline Warming + Precipitation increase & $5.4 \pm 1.6$ & $2.1 \pm 1.8$ & $1.5 \pm 0.8$ & $36.1 \pm 7.8$ \\
\hline \multicolumn{5}{|l|}{ Significance ( $F$-values) } \\
\hline Block $(B)$ & 0.645 & $29.771 *$ & 0.370 & 12.253 \\
\hline $\operatorname{Precipitation}(P)$ & 0.067 & 3.348 & 0.304 & 8.440 \\
\hline Warming $(W)$ & 1.428 & 0.064 & 0.027 & 1.035 \\
\hline Sampling time $(T)$ & $5.347 * *$ & $20.215^{* * *}$ & $4.207 * *$ & $21.378 * * *$ \\
\hline$P \times W$ & 0.270 & 2.946 & 1.248 & 0.098 \\
\hline$P \times T$ & 1.409 & 0.349 & 0.171 & 0.704 \\
\hline$W \times T$ & 0.383 & 0.121 & 0.401 & 1.191 \\
\hline$P \times W \times T$ & 0.338 & 1.725 & 0.978 & 0.734 \\
\hline
\end{tabular}

a) Data are presented as Mean \pm SE, $n=6, F$-values of the repeated-measures ANOVA were shown. b) Watering was not carried out on May 25, 2005, and the plots in treatments of Precipitation $(P)$ and Warming plus Precipitation $(W P)$ were added to control and Warming $(W)$, respectively. *, $P<0.005$; **, $P<0.01 ; * * *, P<0.01$.

structures between treatments. Significant intra-annual changes were found in the number of arbuscules and vesicles $(P=0.002$ and $<0.001$, respectively), and in total PRLC $(P=0.001)$. Significant fewer hyphal coils $(P=0.027)$ and less total PRLC $(P=0.032)$ were found in August 2006 as compared with August 2005 (Table 1).

\subsection{AMF spore community composition}

A total of 22 AMF morpho-species, belonging to 11 genera (Glomus, Claroideoglomus, Rhizophagus, Septoglomus, Funneliformis, Diversispora, Ambispora, Acaulospora, Entrophospora, Scutellospora and Gigaspora), were found at the study site (Table 2). Spores of two genera Claroideoglomus and Ambispora had higher spore production, accounting for $38.4 \%$ and $36.4 \%$ of the total number of spores. Spores of Glomus were the third in spore production, and spores of Entrophospora, Scutellospora, and Gigaspora averaged less than $0.3 \%$ each. Three "spore abundant" species (Claroideoglomus etunicatum, Ambispora gerdemannii, and Glomus albidum) accounted for over three quarters of the AMF spores in the natural conditions.

The results of Indicator Species Analysis using PC-ORD are shown in Table 3. Am. gerdemannii was identified as an indicator species for increased precipitation, as it was found to sporulate more in plots with increased precipitation. $G$. albidum and $R$. fasciculatum were most abundant in 2005 , while Am. gerdemannii, G. aggregatum, and S. calospora were most abundant in 2006. With respect to seasonal fluctuation in abundance, spores of Am. gerdemannii and F. caledonium were significantly higher in Spring, while spores of $C$. etunicatum, $R$. fasciculatum, and $G$. warcupii did not become abundant until the fall.

\subsection{Different responses of C. etunicatum and Am. ger- demannii to climate changes}

To evaluate the influence of elevated temperatures and increased precipitation on spore production of $C$. etunicatum vs. Am. gerdemannii, intra- and inter-annual changes of 
Table 2 The relative abundance (RA) of AMF species at the grassland study site in Inner-Mongolia at four sampling times ${ }^{\mathrm{a}}$

\begin{tabular}{|c|c|c|c|c|c|c|}
\hline AM Fungal species & May 25,2005 & Aug. 1, 2005 & Sept. 22, 2005 & Aug. 4, 2006 & Year & Season \\
\hline Claroideoglomus etunicatum & $29.6 \pm 2.4$ & $35.4 \pm 2.1$ & $48.4 \pm 3.2$ & $41.4 \pm 2.3$ & 2.81 & $13.59 * * *$ \\
\hline Ambispora gerdemannii & $39.3 \pm 2.4$ & $32.9 \pm 3.4$ & $23.6 \pm 3.4$ & $40.0 \pm 3.1$ & 2.60 & $6.39 * *$ \\
\hline Glomus albidum & $17.2 \pm 2.6$ & $20.1 \pm 3.2$ & $19.0 \pm 2.3$ & $10.8 \pm 1.4$ & $7.14 * *$ & 0.36 \\
\hline Funneliformis badium & $5.9 \pm 1.6$ & $5.6 \pm 1.2$ & - & $4.9 \pm 1.2$ & 0.19 & $7.40^{* *}$ \\
\hline Rhizophagus fasciculatum & $1.8 \pm 0.7$ & $2.6 \pm 1.1$ & $4.4 \pm 1.7$ & $0.1 \pm 0.1$ & 2.60 & 1.58 \\
\hline Funneliformis caledonium & $3.4 \pm 2.3$ & $0.6 \pm 0.3$ & - & $0.0 \pm 0.0$ & 0.76 & 2.36 \\
\hline Glomus warcupii & - & - & $1.6 \pm 1.1$ & - & 0.00 & 2.76 \\
\hline Septoglomus constrictum & $0.2 \pm 0.2$ & $1.2 \pm 0.5$ & - & $0.3 \pm 0.3$ & $4.43^{*}$ & $4.87 * *$ \\
\hline Glomus aggregatum & - & - & - & $0.8 \pm 0.4$ & $9.05 * *$ & 0.00 \\
\hline Diversispora versiforme & $0.8 \pm 0.8$ & - & - & - & 0.00 & 1.31 \\
\hline Rhizophagus intraradices & - & - & $0.7 \pm 0.7$ & - & 0.00 & 1.40 \\
\hline Rhizophagus clarum & - & - & $0.7 \pm 0.7$ & $0.5 \pm 0.3$ & 0.09 & 1.13 \\
\hline Glomus sp.1 & - & $0.3 \pm 0.3$ & $0.1 \pm 0.1$ & - & 1.88 & 1.02 \\
\hline Acaulospora sp. 1 & $0.9 \pm 0.3$ & $0.4 \pm 0.2$ & $0.9 \pm 0.4$ & $0.3 \pm 0.2$ & 0.00 & 1.40 \\
\hline Acaulospora mellea & $0.0 \pm 0.0$ & $0.0 \pm 0.0$ & $0.2 \pm 0.2$ & - & 0.03 & 2.30 \\
\hline Acaulospora sp. 2 & $0.5 \pm 0.4$ & $0.5 \pm 0.3$ & - & - & 0.05 & 1.27 \\
\hline Acaulospora sp. 3 & $0.2 \pm 0.1$ & $0.2 \pm 0.1$ & - & - & 2.52 & 1.68 \\
\hline Acaulospora sp.4 & $0.1 \pm 0.1$ & - & - & - & 2.21 & 1.29 \\
\hline Acaulospora sp.5 & - & - & $0.0 \pm 0.0$ & - & 0.00 & 1.31 \\
\hline Entrophospora infrequens & - & - & $0.3 \pm 0.2$ & $0.2 \pm 0.1$ & 1.10 & 1.50 \\
\hline Scutellospora calospora & $0.1 \pm 0.1$ & $0.1 \pm 0.1$ & - & $0.7 \pm 0.3$ & $5.70^{*}$ & 0.21 \\
\hline Gigaspora gigantea & - & $0.0 \pm 0.0$ & - & - & 1.98 & 1.31 \\
\hline
\end{tabular}

a) Mean values and SE (\%) of 24 samples are shown. Effects of year and season were evaluated using general linear model in SPSS (version 16.0) and $F$-values were shown. *, $P<0.05$; **, $P<0.01$; ***, $P<0.001$. "-" indicates that the species is absent and " 0.0 " represents the rounded value of a very low RA.

Table 3 Indicator species for different treatments, years and seasons, according to indicator species analysis with a maximum indicator value (IV)

\begin{tabular}{|c|c|c|c|c|}
\hline Grouped by & Preferred group & Indicator species & $I V$ & $P$ \\
\hline \multicolumn{5}{|l|}{ Precipitation } \\
\hline & Increased precipitation & Ambispora gerdemannii & 54.8 & 0.023 \\
\hline \multicolumn{5}{|l|}{ Year } \\
\hline & 2005 & Glomus albidum & 60.8 & 0.006 \\
\hline & 2005 & Rhizophagus fasciculatum & 41.8 & 0.003 \\
\hline & 2006 & Glomus aggregatum & 16.7 & 0.005 \\
\hline & 2006 & Scutellospora calospora & 22.2 & 0.003 \\
\hline \multicolumn{5}{|l|}{ Season } \\
\hline & Spring & Ambispora gerdemannii & 39.6 & 0.012 \\
\hline & Spring & Funneliformis caledonium & 30.6 & 0.001 \\
\hline & Autumn & Claroideoglomus etunicatum & 41.6 & 0.000 \\
\hline & Autumn & Glomus warcupii & 12.5 & 0.031 \\
\hline
\end{tabular}

a) Significant $P$-values indicate significant preferences to increased precipitation, specific year or seasons.

these two abundant sporulating species were calculated. Significant impacts of precipitation were found in the first half of the growth season (from May 25 to August 1) (see the left four columns in Figure 1(a) and (b)). Under ambient precipitation, the relative abundance of $C$. etunicatum increased and the relative abundance of Am. gerdemannii decreased; increased precipitation significantly reduced the increase of relative abundance of $C$. etunicatum (see the left four columns in Figure 1(a)) and alleviated the decrease of the relative abundance of Am. gerdemannii (see the left four columns in Figure 1(b)) during the first half of the growth season. Warming showed no significant effects on relative abundance of $C$. etunicatum and Am. gerdemannii. Both warming and increased precipitation had no significant 


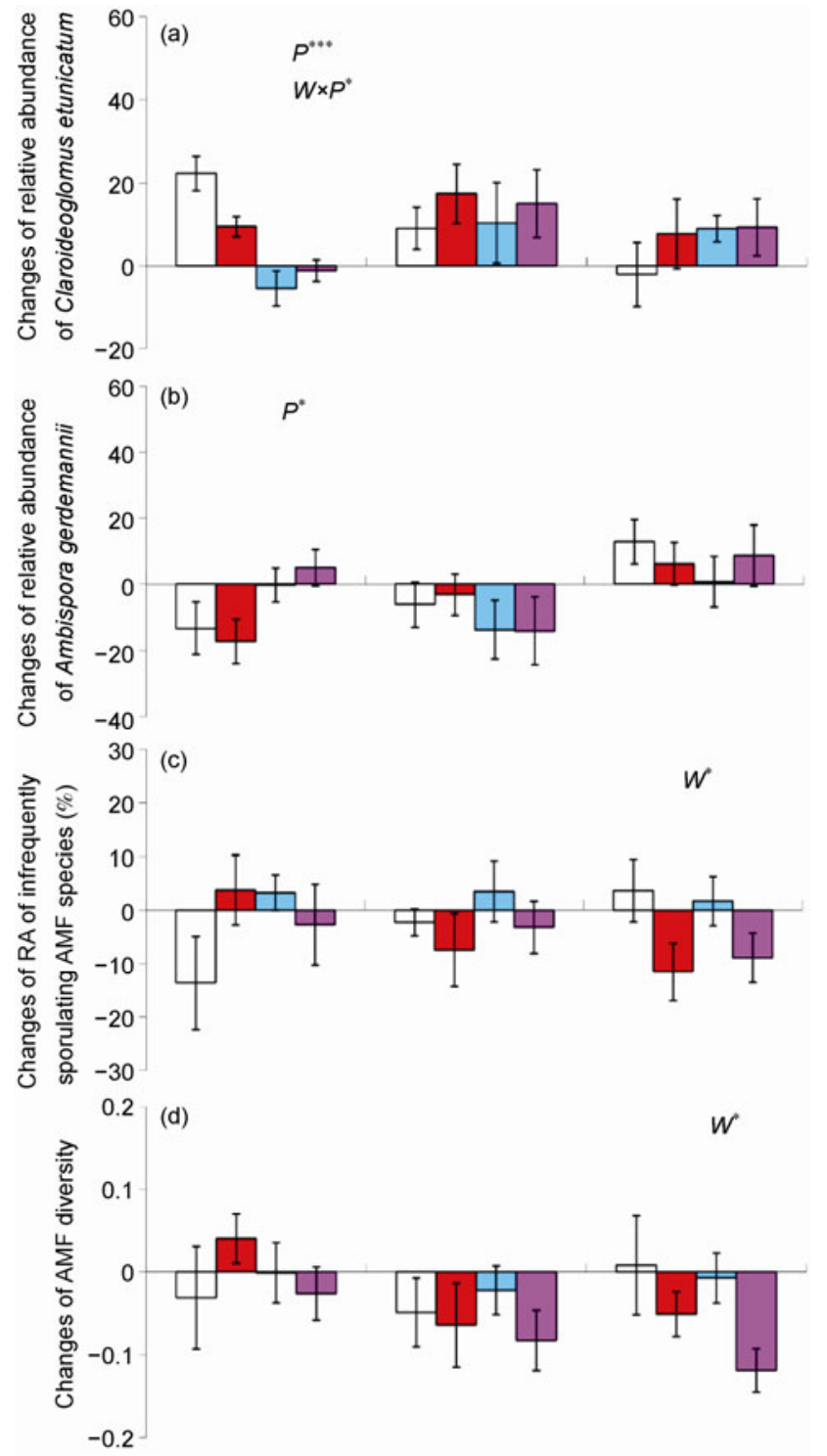

Figure 1 Intra- and inter-annual changes in relative abundance of two abundant sporulating AMF species, (a) Claroideoglomus etunicatum and (b) Ambispora gerdemannii; (c) the relative abundance (RA) of infrequently sporulating AMF species; and (d) species diversity (Simpson's Diversity Index) of the AMF community. Treatments include control ( $\square$ ), artificial warming $(W, \square)$, enhanced precipitation $(P, \square)$ and both warming and enhanced precipitation (WP, $\square)$. Bars represent $1 \mathrm{SE}$. The significant impacts of $W, P$ and $W \times P$ are shown as $* P<0.05$, *** $P<0.001$.

effect on inter-annual variation in the relative abundance of C. etunicatum and Am. gerdemannii.

To evaluate the influence of warming and precipitation on spore proportion of C. etunicatum and Am. gerdemannii, DRA (Difference of Relative Abundance) between the two dominant species were calculated (Table 4). Am. gerdemannii was the most abundant species and $C$. etunicatum took the second place on May 25. At the end of the growth season, however, $C$. etunicatum took the first place and Am. gerdemannii was at the second place. Owing to the proportion shifts of $C$. etunicatum and Am. gerdemannii, a signifi- cantly lower DRA between $C$. etunicatum and Am. gerdemannii was found in the warming treatment $(W)$ on May 25 and in precipitation treatments $(P$ and $W P)$ on August 1 in 2005 as compared with control. Warming and increased precipitation had significant effects on DRA between the two species at early and middle stage of the growth season in 2005 , respectively.

\subsection{Effects of warming and watering on infrequent sporulating AMF and diversity}

Both the relative abundance of infrequent sporulating species and species diversity differed between the warming and increased precipitation treatments (Figure 1(c) and (d)). Neither the warming nor increased precipitation treatments significantly affected the amount of intra-annual variations in abundance of rare species (see the left and middle four columns in Figure 1(c)). Warming had a significant effect on the inter-annual variation in the relative abundance of spore-non-abundant species (see the right four columns in Figure 1(c)).

The impact of both warming and increased precipitation on species diversity was similar to the effects of these treatments on the relative abundance of infrequent sporulating species (Figure 1(d)). While neither treatment altered the pattern of intra-annual variation (see the left and middle four columns in Figure 1(d)), the warming treatment significantly affected the pattern of inter-annual changes in the species diversity of AMF fungi (see the right four columns in Figure 1(d)). After one year, the proportion of spore-nonabundant AMF species in the WP treatment was significantly lower than in the control (one-way ANOVA, $P<0.05$; also see the right four columns in Figure 1(d)). As species diversity and the proportion of rare species tend to be correlated, the similar patterns observed for these two variables were not unexpected.

\subsection{The relationship between plant and AMF commu- nity compositions}

The results of the Mantel test on the associations between compositions of the plant and AMF community are presented in Table 5. The plant communities in 2005 and 2006 were significantly correlated as it is expected in experimental plots in which the vegetation is left from one year to the other. However, compositions of AMF communities in the experimental plots were not significantly correlated, indicating that sporulation varies greatly between years. No significant correlation was found between the plant and the AMF communities in 2006, and a marginal correlation $(P=0.11)$ between plant and the AMF communities were found in 2005. Interestingly, the plant community in 2006 was significantly positively correlated with the AMF community in 2005, indicating that AMF community may exert influences on plant communities. 
Table 4 Difference of relative abundance (DRA) between two abundant sporulating AMF species, Claroideoglomus etunicatum and Ambispora gerdemannii, under warming and precipitation treatment ${ }^{\mathrm{a})}$

\begin{tabular}{|c|c|c|c|c|}
\hline \multirow{2}{*}{ Treatments } & \multicolumn{2}{|c|}{2005} & \multicolumn{2}{|c|}{2006} \\
\hline & May $25^{\text {b) }}$ & Aug. 1 & Sep. 22 & Aug. 4 \\
\hline Control & $-2.1 \pm 5.2$ & $23.3 \pm 8.0$ & $38.1 \pm 6.8$ & $0.8 \pm 12.6$ \\
\hline Precipitation increase & - & $-5.9 \pm 11.3$ & $18.2 \pm 11.3$ & $2.4 \pm 9.1$ \\
\hline Warming + Precipitation increase & - & $-13.4 \pm 9.0$ & $15.7 \pm 17.6$ & $-12.7 \pm 11.9$ \\
\hline \multicolumn{5}{|l|}{ Significance ( $P$-values) } \\
\hline Warming $(W)$ & $0.047 *$ & 0.162 & 0.770 & 0.971 \\
\hline Precipitation $(P)$ & - & $0.009 * *$ & 0.996 & 0.198 \\
\hline$W \times P$ & - & 0.580 & 0.758 & 0.151 \\
\hline
\end{tabular}

a) Data are presented as Mean \pm SE. b) Watering was not carried out on May 25, 2005, and the plots in treatments of Precipitation $(P)$ and Warming plus Precipitation $(W P)$ were added to control and Warming $(W)$, respectively.

Table 5 Mantel test on intra- and inter-annual association between plant and AMF community composition at a Mongolian Grassland site ${ }^{\text {a) }}$

\begin{tabular}{cccc}
\hline & Plant-2005 & Plant-2006 & AMF-2005 \\
\hline Plant-2005 & 1.000 & & \\
Plant-2006 & $0.703^{* * *}$ & 1.000 & $0.154^{*}$ \\
AMF-2005 & $0.121^{+}$ & 0.006 & 1.000 \\
AMF-2006 & 0.053 & 0.057 & 1.000 \\
\hline
\end{tabular}

a) Standardized Mantel statistics $(r)$ are given:,$+ *$ and $* * *$ indicate significance at the $0.15,0.05$ and 0.001 level, respectively.

The relationships between two abundant sporulating AMF species and the ground cover by two dominant plant functional groups (i.e. grasses and forbs) are shown in Figure 2. As the abundance of $C$. etunicatum increases, relative to that of Am. gerdemannii, the percent cover of grass significantly decreases, whereas forbs significantly increased.

For a more detailed analysis we divided the plots into $C$. etunicatum dominated (DRA $\geqslant 10 \%), A m$. gerdemannii dominated (DRA $\leqslant-10 \%$ ), and remaining plots $(-10 \%<$ DRA $<10 \%)$. The mean relative ground cover by plant species in these C. etunicatum-dominated and Am. gerdemanniidominated plots were then plotted in Figure 3. Linear regressions were calculated for grasses and forbs, whose slopes differ significantly $(t=9.84, P<0.01)$. The steep and

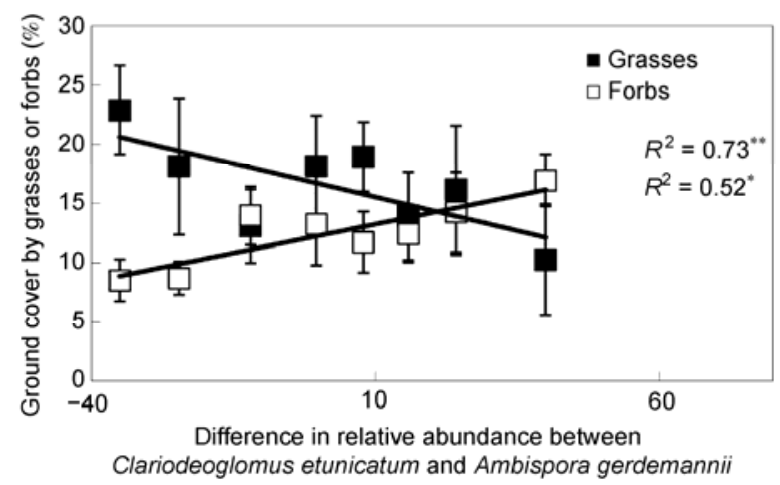

Figure 2 Relationship between ground cover of grasses and forbs and the difference in relative abundance (DRA) between Claroideoglomus etunicatum and Ambispora gerdemannii. Pearson correlation coefficients $(R)$ are given. $*$ and $* *$ indicate significance at the 0.05 and 0.01 level, respectively.

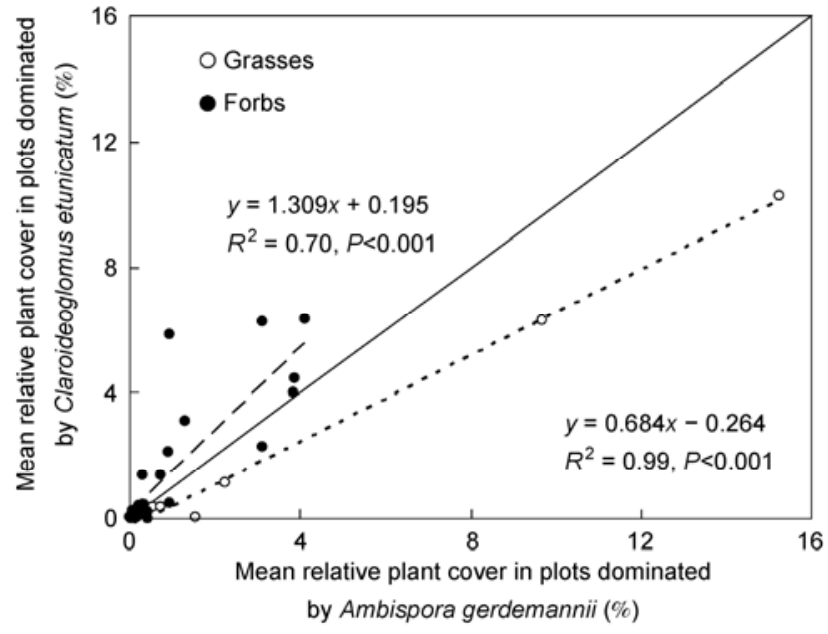

Figure 3 Mean relative coverage of grasses and forbs in Ambispora gerdemannii and Claroideoglomus etunicatum dominated plots. Dotted and dash lines show the linear regressions for grasses and forbs.

shallow regression slopes denote different preferences of grasses and forbs to C. etunicatum and Am. gerdemannii dominated microsites.

Preference index of plant species to $C$. etunicatum dominated plots, defined as the ratio of the mean relative coverage of a plant species in $C$. etunicatum dominated plots to the mean relative cover of it in both $C$. etunicatum- and Am. gerdemannii-dominated plots, were shown in Figure 4. Members of Gramineae (grasses) exhibited significantly lower preference index than species in Compositae, Fabaceae, Liliaceae, and Rosaceae. An F-test on this preference 


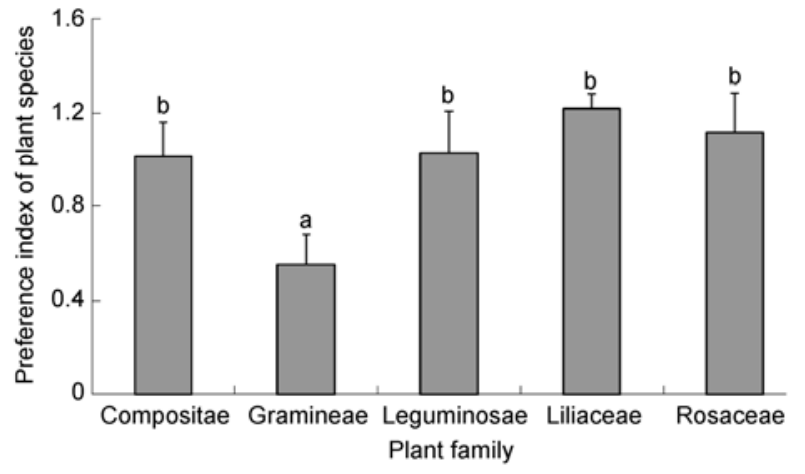

Figure 4 Preference index of members of different plant families to Claroideoglomus etunicatum dominated plots. The bars represent means and $1 \mathrm{SE}$ of preference index. Different letters denote significant differences $(P<0.05)$ according to one-way ANOVA.

data suggests that plants within a family show more similar preferences in choosing plots dominated by different AMF species than plants from different families, since the variation between families was significantly higher than that within families $(F=3.816, P=0.018)$.

\section{Discussion}

How mycorrhizal plant-fungal associations will be affected by changing climate has become a key challenge for mycorrhizal research in the new millennium [41]. Global climate change may have direct or plant-soil-mediated indirect effects on the physiology of mycorrhizal fungi (e.g. hyphal growth, sporulation, nutrient uptake) and the species composition of these below-ground communities [42,43]. While many factors, including plant nutrient, light intensity, and plant community composition, have been suggested to influence the development of arbuscular mycorrhizal fungi and the formation of mycorrhizae [44-51], soil temperature and moisture are undoubtedly two major factors [52,53]. It has been documented that increase of soil temperature may enhance growth of extraradical mycorrhizal hyphae, root length colonized by mycorrhizal fungi, fungal TRFs in soil and plant roots $[19,54,55]$. Changes in precipitation and soil moisture could also affect fungal abundance and litter decomposition [56]. Since the optimal growth temperatures and moistures may vary among fungal species [57], global warming and concurrent changes in precipitation progress could also affect the competitive balance between different AMF species and composition of AMF communities.

\subsection{Fluctuations in the occurrence of rare AMF species and community diversity}

In our study, artificial warming significantly reduced the relative abundances of species sporulating little and/or rarely and the species diversity of the AMF community (Figure 1 ), perhaps as a result of spore-abundant species performing better on average at higher temperatures. If abundant sporulating species and rarely sporulating respond differently to climate change, the competitive balance between dominant and rare species may be altered, and the species diversity may change. Negative impacts on AMF community diversities may affect the functioning of grassland ecosystems, given there are positive correlations between plant and AMF communities [23].

Rare species are important components of ecosystems, and their abundance, along with species richness can be important determinants of ecosystem functioning. Compared to dominant species, rare species face heightened extinction risks under unfavorable or stressful conditions.

Although spore abundance often does not completely reflect the fungal biomass in roots and soils [58-60], spore abundance of AMF species is still a good indicator of reproductive success. A decrease in spore density, especially for a species with low spore production, likely indicates reduced population viability which could result in local extinction. The species richness and species diversity of an AMF community depend, therefore, much on the occurrence of species with low sporulation rates.

\subsection{Environmental factors and abundant sporulating AMF species}

Our results showed that both the warming and water-addition treatments influenced the relative sporulation between C. etunicatum and Am. gerdemannii. The effects of these treatments were strongest during the first half of the growing season (Figure 2). This result implies that, in comparison with $C$. etunicatum, Am. gerdemannii prefers warmer and wetter early-season soil conditions. Compared to rare species, dominant species usually face a smaller threat of extinction through changes in their environment. Similarly, higher temperatures and increased precipitation may thus only alter the proportion of abundant sporulating AMF species, but not decide whether sporulation occurs or not. Higher temperatures and increased precipitation could therefore change the composition of AMF communities by altering the relative spore production of different AMF species.

It has been suggested that the AMF species composition, but not necessarily the species richness, is related to above ground plant biodiversity in ecosystems [61]. The changes in relative abundance of common species should therefore be involved in the plant-AMF interactions. Positive or negative feedbacks are expected to occur between plant and mycorrhizal fungal communities $[49,62]$, with implications for ecosystem functioning. In these feedback models, the magnitude of the benefit for both plant and fungal partners is the key to determine the structure and stability of both plant and fungal communities [62].

We found that the DRA between $C$. etunicatum and Am. gerdemannii was negatively correlated with the percent cover of grasses, and positively correlated with the percent 
cover of forbs, which implies that shifts in the dominance of spore-abundant AMF species may be related to the structural changes of the plant community. The different responses of grasses and forbs to the DRA between AMF species might result from asymmetrical benefits (to the grasses vs. forbs) from these two spore-abundant AMF species or different host preferences of these two AMF species to grasses and forbs. In grasslands, compensatory effects between functional groups are thought to be an important mechanism maintaining ecosystem stability [63]. Our results indicate that AMFs may be involved in creating these compensatory effects. In a status report for the BIOLOG project in Europe, which seeks to examine mycological responses to climate change, Hempel et al. [64] found that suppressing AMFs with fungicide significantly increased plant ${ }^{15} \mathrm{~N}$-nitrate uptake in grasses, while reducing it in herbs. Possible explanation was that fungicide-sensitive and fungicide-resistant AMF species benefit herbs to a different degree than grasses different amounts, which agree with our observations.

This study has shown the existence of different preferences of grasses and forbs to habitats dominated by different AMF species. Compared with the numerous plant species, the number of AMF species is quite limited. Many AMF species are considered to have broad host range, and some distribute in many areas of the world. Although lack of specificity, whether any preference exist in the plantAMF associations is still not known. Our results suggest that members of different plant families may have preferences to assemblages with different dominant AMF species. Changes in the occurrence of dominant AMF species could thus induce changes in plant community composition.

\subsection{The role of AMF community, driver or passenger?}

Hart et al. [65] gave the "driver/passenger hypothesis", in which mycorrhizal fungal community could act as either driver or passenger in the interaction with plant community. In the driver hypothesis, interactions within mycorrhizal fungal communities are responsible for changes in the plant community, while in the passenger hypothesis, mycorrhizal community dynamics are only a by-product of changes in the plant community [65].

In studies which correlate plant and mycorrhizal fungal diversity, it is usually impossible to determine whether plant diversity causes mycorrhizal diversity or vice versa [66]. Although it has been suggested that mycorrhizal diversity may determine the diversity and productivity of an ecosystem [23,24], many researchers believe that plants can regulate mycorrhizal diversity and community structure [66-68]. In feedback models, a "circular" interaction is implied between plant and AMF communities [62,69]. That is, plant and AMF diversity are interdependent, serving as both cause and effects in these models. These feedback models should be extended to consider the effects of environmental change, as environmental variables may influence both plant and AMF communities.

Under future climate change, the relative sensitivities of plant and AMF communities to environmental signals will be the key to determining cause and effect. In detail, the more sensitive mycorrhizal partner (i.e. either the plant or the AMF) will respond immediately to any environmental change, and will therefore act as the cause of change in diversity. We have found that the plant communities were more stable than the AMF communities, perhaps because most plant species are perennial in this grassland ecosystem. However, we also found that the plant community composition in 2006 was correlated rather with the mycorrhizal community in 2005 than that in 2006, implying that changes in AMF community might cause changes in the plant community the following year. Our result seems to support the diver hypothesis and the relative sensitivities of the plant and AMF communities may be the key in determining who the driver is in the plant-AMF interactions. In ecosystems subjected to frequent disturbance (e.g. flood, drought, or extreme temperatures), the more sensitive AMF communities will probably act as the driver and play a much important role in the plant-AMF feedbacks.

We are grateful to Dr. He Xinhua for his comments and suggestions on an early version of this manuscript and Professor Bernhard Schmid for his kind help in statistical analyses. This work supported by the part of a comprehensive research project (Global Change Multi-Factor ExperimentDuolun) conducted by the Institute of Botany, Chinese Academy of Sciences, the National Natural Science Foundation of China (31170495 and 30970497), a Knowledge Innovation Project of the Chinese Academy of Sciences (KSCX2-SW-127) and State Key Laboratory of Vegetation and Environmental Change, Institute of Botany, Chinese Academy of Sciences.

1 IPCC. Climate Change 2007: The Physical Science Basis. Contribution of Working Group I to the Fourth Assessment Report of the Intergovernmental Panel on Climate Change. Cambridge and New York: Cambridge University Press, 2007

2 Lieth H F H. Patterns of Primary Productivity in the Biosphere. Stroudsberg, PA: Hutchinson \& Ross, 1978. 342

3 Ellis J E. The grazing lands of northern China: Ecology, society, and land use. In: National Research Council, ed. Grassland and Grassland Sciences in Northern China. Washington, D.C., USA: National Academy Press, 1992. 9-36

4 Zhang X S. Northern China. In: National Research Council, ed. Grassland and Grassland Sciences in Northern China. Washington, D. C., USA: National Academy Press, 1992

5 Yang $\mathrm{H}, \mathrm{Wu} \mathrm{M}$, Liu W, et al. Community structure and composition in response to climate change in a temperate steppe. Global Change Biol, 2011, 17: 452-465

6 Xiao X, Ojima D S, Parton W J, et al. Sensitivity of Inner Mongolia grasslands to climate change. J Biogeogr, 1995, 22: 643-648

7 Bai W M, Wan S Q, Niu S L, et al. Increased temperature and precipitation interact to affect root production, mortality, and turnover in a temperate steppe: Implications for ecosystem C cycling. Global Change Biol, 2009, 16: 1306-1316

8 Zhang N L, Xia J Y, Yu X J, et al. Soil microbial community changes and their linkages with ecosystem carbon exchange under asymmetrically diurnal warming. Soil Biol Biochem, 2011, 43: 2053-2059

9 Bi J, Zhang N L, Liang Y, et al. Interactive effects of water and nitrogen addition on soil microbial communities in a semiarid steppe. $\mathrm{J}$ Plant Ecol, 2012, 5: 320-329

10 Liu W X, Zhang Z, Wan S Q. Predominant role of water in regulating 
soil and microbial respiration and their responses to climate change in a semiarid grassland. Global Change Biol, 2009, 15: 184-195

11 Yan L M, Chen S P, Huang J H, et al. Differential responses of autoand heterotrophic soil respiration to water and nitrogen addition in a semiarid temperate steppe. Global Change Biol, 2010, 16: 2345-2357

12 Yan L M, Chen S P, Huang J H, et al. Water regulated effects of photosynthetic substrate supply on soil respiration in a semiarid steppe. Global Change Biol, 2011, 17: 1990-2001

13 Miller R M, Kling M. The importance of integration and scale in the arbuscular mycorrhizal symbiosis. Plant Soil, 2000, 226: 295-309

14 Miller R M. The ecology of vesicular-arbuscular mycorrhizae in grass-and shrublands. In: Safir G R, ed. Ecophysiology of VA mycorrhizal plants. Boca Raton, Fla: CRC Press, 1987. 136-170

15 Treseder K K, Cross A. Global distributions of arbuscular mycorrhizal fungi. Ecosystems, 2006, 9: 305-316

16 Fitter A H, Heinemeyer A, Staddon P L. The impact of elevated $\mathrm{CO}_{2}$ and global climate change on arbuscular mycorrhizas: A mycocentric approach. New Phytol, 2000, 147: 179-187

17 Staddon P, Heinemeyer A, Fitter A. Mycorrhizas and global environmental change: Research at different scales. Plant Soil, 2002, 244: $253-261$

18 Heinemeyer A, Fitter A H. Impact of temperature on the arbuscular mycorrhizal (AM) symbiosis: Growth responses of the host plant and its AM fungal partner. J Exp Bot, 2004, 55: 525-534

19 Rillig M C, Wright S F, Shaw M R, et al. Artificial climate warming positively affects arbuscular mycorrhizae but decreases soil aggregate water stability in an annual grassland. Oikos, 2002, 97: 52-58

20 Staddon P L, Thompson K, Jakobsen I, et al. Mycorrhizal fungal abundance is affected by long-term climatic manipulations in the field. Global Change Biol, 2003, 9: 186-194

21 Heinemeyer A, Ridgway K P, Edwards E J, et al. Impact of soil warming and shading on colonization and community structure of arbuscular mycorrhizal fungi in roots of a native grassland community. Global Change Biol, 2003, 10: 52-64

22 Fitter A H, Heinemeyer A, Husband R, et al. Global environmental change and the biology of arbuscular mycorrhizas: Gaps and challenges. Can J Botany-Revue Canadienne De Botanique, 2004, 82: 1133-1139

23 van der Heijden M G A, Klironomos J N, Ursic M, et al. Mycorrhizal fungal diversity determines plant biodiversity, ecosystem variability and productivity. Nature, 1998, 396: 69-72

24 van der Heijden M G A, Verkade S, de Bruin S J. Mycorrhizal fungi reduce the negative effects of nitrogen enrichment on plant community structure in dune grassland. Global Change Biol, 2008, 14: $2626-2635$

25 Anderson R C, Liberta A E, Dickman L A. Interaction of vascular plants and vesicular-arbuscular mycorrhizal fungi across a soil moisture-nutrient gradient. Oecologia,1984, 64: 111-117

26 Koske R E. Distribution of VA mycorrhizal fungi along a latitudinal temperature-gradient. Mycologia, 1987, 79: 55-68

27 Allen E B, Allen M F, Helm D J, et al. Patterns and regulation of mycorrhizal plant and fungal diversity. Plant Soil, 1995, 170: 47-62

28 Antoninka A, Reich P B, Johnson N C. Seven years of carbon dioxide enrichment, nitrogen fertilization and plant diversity influence arbuscular mycorrhizal fungi in a grassland ecosystem. New Phytol, 2011, 192: 200-214

29 Landis F C, Gargas A, Givnish T J. Relationships among arbuscular mycorrhizal fungi, vascular plants and environmental conditions in oak savannas. New Phytol, 2004, 164: 493-504

30 Niu S L, Wu M Y, Han Y, et al. Water-mediated responses of ecosystem carbon fluxes to climatic change in a temperate steppe. New Phytol, 2008, 177: 209-219

31 Koske R E, Tessier B. A convenient, permanent slide mounting medium. Mycol Soc Am Newslett, 1983, 34: 59

32 Mcgonigle T P, Miller M H, Evans D G, et al. A new method which gives an objective-measure of colonization of roots by vesicular arbuscular mycorrhizal fungi. New Phytol, 1990, 115: 495-501

33 Daniels B A, Skipper H D. Methods for the recovery and quantitative estimation of propagules from soil. In: Schenck N C, ed. Method and
Principles of Mycorrhiza Research. St Paul, USA: American Society for Phytopathology, 1982

34 Krüger M, Krüger C, Walker C, et al. Phylogenetic reference data for systematics and phylotaxonomy of arbuscular mycorrhizal fungi from phylum to species level. New Phytol, 2012, 193: 970-984

35 Schüßler A, Schwarzott D, Walker C. A new fungal phylum, the Glomeromycota: Phylogeny and evolution. Mycol Res, 2001, 105: 1413-1421

36 Oehl F, Silva G A, Goto B T, et al. Glomeromycota: Three new genera and glomoid species reorganized. Mycotaxon, 2011, 116: $75-120$

37 Schüßler A, Walker C. The Glomeromycota: A species list with new families and genera. Edinburgh \& Kew, UK: The Royal Botanic Garden; Munich, Germany: Botanische Staatssammlung Munich; Oregon, USA: Oregon State University, 2010

38 Simpson E H. Measurement of Diversity. Nature, 1949, 163: 688

39 McCune B, Mefford M. PC-ORD multivariate analysis of ecological data. Version 5.0. MjM Software, Gleneden Beach, Oregon, USA, 2006

40 De Cáceres M D, Legendre P. Associations between species and groups of sites: Indices and statistical inference. Ecology, 2009, 90: 3566-3574

41 Söderström B. Challenges for mycorrhizal research into the new millennium. Plant Soil, 2002, 244: 1-7

42 Rillig M C, Treseder K K, Allen M F. Global change and mycorrhizal fungi. In: Heijden M G A, Sanders I R, eds. Mycorrhizal Ecology. New York, USA: Springer-Verlag, 2002. 135-160

43 Rillig M C. Arbuscular mycorrhizae and terrestrial ecosystem processes. Ecol Lett, 2004, 7: 740-754

44 Furlan V, Fortin J A. Effects of light-intensity on formation of vesicular-arbuscular endomycorrhizas on Allium-Cepa by GigasporaCalospora. New Phytol, 1977, 79: 335-340

45 Jasper D A, Abbott L K, Robson A D. Soil disturbance reduces the infectivity of external hyphae of vesicular arbuscular mycorrhizal fungi. New Phytol, 1989, 112: 93-99

46 Jasper D A, Abbott L K, Robson A D. Hyphae of a vesicular arbuscular mycorrhizal fungus maintain infectivity in dry soil, except when the soil is disturbed. New Phytol, 1989, 112: 101-107

47 Ngwene B, Gabriel E, George E. Influence of different mineral nitrogen sources $\left(\mathrm{NO}_{3}{ }^{-} \mathrm{N}\right.$ vs. $\left.\mathrm{NH}_{4}{ }^{+}-\mathrm{N}\right)$ on arbuscular mycorrhiza development and $\mathrm{N}$ transfer in a Glomus intraradices-cowpea symbiosis. Mycorrhiza, 2013, 23: 107-117

48 Jasper D A, Abbott L K, Robson A D. The Effect of soil disturbance on vesicular arbuscular mycorrhizal fungi in soils from different vegetation types. New Phytol, 1991, 118: 471-476

49 Bever J D. Dynamics within mutualism and the maintenance of diversity: Inference from a model of interguild frequency dependence. Ecol Lett, 1999, 2: 52-61

50 Smith M D, Hartnett D C, Wilson G W T. Interacting influence of mycorrhizal symbiosis and competition on plant diversity in tallgrass prairie. Oecologia, 1999, 121: 574-582

51 Lilleskov E A, Parrent J L. Can we develop general predictive models of mycorrhizal fungal community-environment relationships? New Phytol, 2007, 174: 250-256

52 Heinemeyer A, Fitter A H. Impact of temperature on the arbuscular mycorrhizal (AM) symbiosis: Growth responses of the host plant and its AM fungal partner. J Exp Bot, 2004, 55: 525-534

53 Hawkes C V, Hartley I P, Ineson P, et al. Soil temperature affects carbon allocation within arbuscular mycorrhizal networks and carbon transport from plant to fungus. Global Change Biol, 2008, 14: 11811190

54 Gavito M E, Schweiger P, Jakobsen I. P uptake by arbuscular mycorrhizal hyphae: Effect of soil temperature and atmospheric $\mathrm{CO}_{2}$ enrichment. Global Change Biol, 2003, 9: 106-116

55 Anderson I C, Drigo B, Keniry K, et al. Interactive effects of preindustrial, current and future atmospheric $\mathrm{CO}_{2}$ concentrations and temperature on soil fungi associated with two Eucalyptus species. Fems Microbiol Ecol, 2013, 83: 425-437

56 Hawkes C V, Kivlin S N, Rocca J D, et al. Fungal community 
responses to precipitation. Global Change Biol, 2011, 17: 1637-1645

57 Gavito M E, Olsson P A, Rouhier H, et al. Temperature constraints on the growth and functioning of root organ cultures with arbuscular mycorrhizal fungi. New Phytol, 2005, 168: 179-188

58 Clapp J P, Young J P W, Merryweather J W, et al. Diversity of fungal symbionts in arbuscular mycorrhizas from a natural community. New Phytol, 1995, 130: 259-265

59 Sanders I R. Plant and arbuscular mycorrhizal fungal diversity-are we looking at the relevant levels of diversity and are we using the right techniques? New Phytol, 2004, 164: 415-418

60 Hempel S, Renker C, Buscot F. Differences in the species composition of arbuscular mycorrhizal fungi in spore, root and soil communities in a grassland ecosystem. Environ Microbiol, 2007, 9: 1930-1938

61 Börstler B, Renker C, Kahmen A, et al. Species composition of arbuscular mycorrhizal fungi in two mountain meadows with differing management types and levels of plant biodiversity. Biol Fert Soils, 2006, 42: 286-298

62 Johnson N C, Hoeksema J D, Bever J D, et al. From Lilliput to Brobdingnag: Extending models of mycorrhizal function across scales. Bioscience, 2006, 56: 889-900

63 Bai Y F, Han X G, Wu J G, et al. Ecosystem stability and compensatory effects in the Inner Mongolia grassland. Nature, 2004,
431: $181-184$

64 Hempel S, Spindler S, Renker C, et al. Structural and functional diversity of arbuscular mycorrhizal fungi: Function for grassland ecosystems and indicative values for the assessment of sustainable use. In: BIOLOG, ed. Biodiversity and global change, status report 2005. PT-DLR Environmental Research and Technology, Bonn, 2005

65 Hart M M, Reader R J, Klironomos J N. Life-history strategies of arbuscular mycorrhizal fungi in relation to their successional dynamics. Mycologia, 2001, 93: 1186-1194

66 Johnson D, Ijdo M, Genney D R, et al. How do plants regulate the function, community structure, and diversity of mycorrhizal fungi? J Exp Bot, 2005, 56: 1751-1760

67 Johnson D, Vandenkoornhuyse P J, Leake J R, et al. Plant communities affect arbuscular mycorrhizal fungal diversity and community composition in grassland microcosms. New Phytol, 2003, 161: 503-515

68 Chen X, Tang J J, Fang Z G, et al. Effects of weed communities with various species numbers on soil features in a subtropical orchard ecosystem. Agr Ecosyst Environ, 2004, 102: 377-388

69 Bever J D, Morton J B, Antonovics J, et al. Host-dependent sporulation and species diversity of arbuscular mycorrhizal fungi in a mown grassland. J Ecol, 1996, 84: 71-82

Open Access This article is distributed under the terms of the Creative Commons Attribution License which permits any use, distribution, and reproduction in any medium, provided the original author(s) and source are credited. 